\title{
Kinin B1 receptor: a potential therapeutic target in sepsis-induced vascular hyperpermeability
}

Stéphanie Ruiz ${ }^{1,2 *}$, Fanny Vardon-Bounes ${ }^{1,2}$, Marie Buléon², Céline Guilbeau-Frugier 2,3,4, Marie-Hélène Séguelas ${ }^{2}$, Jean-Marie Conil ${ }^{1}$, Jean-Pierre Girolami ${ }^{2}$, Ivan Tack ${ }^{2,5}$ and Vincent Minville ${ }^{1,2}$

\begin{abstract}
Background: In sepsis, the endothelial barrier becomes incompetent, with the leaking of plasma into interstitial tissues. VE-cadherin, an adherens junction protein, is the gatekeeper of endothelial cohesion. Kinins, released during sepsis, induce vascular leakage and vasodilation. They act via two G-protein coupled receptors: B1 (B1R) and B2 (B2R). $\mathrm{B} 1 \mathrm{R}$ is inducible in the presence of pro-inflammatory cytokines, endotoxins or after tissue injury. It acts at a later stage of sepsis and elicits a sustained inflammatory response. The aim of our study was to investigate the relationships between B1R and VE-cadherin destabilization in vivo in a later phase of sepsis.
\end{abstract}

Methods: Experimental, prospective study in a university research laboratory. We used a polymicrobial model of septic shock by cecal ligation and puncture in C57BL6 male mice or C57BL6 male mice that received a specific B1R antagonist (R-954). We studied the influence of B1R on sepsis-induced vascular permeability $30 \mathrm{~h}$ after surgery for several organs, and VE-cadherin expression in the lung and kidneys by injecting R-954 just before surgery. The 96-h survival was determined in mice without treatment or in animals receiving R-954 as a "prophylactic" regimen (a subcutaneous injection of $200 \mu \mathrm{g} / \mathrm{kg}$, prior to CLP and $24 \mathrm{~h}$ after CLP), or as a "curative" regimen (injection of $100 \mu \mathrm{g} / \mathrm{kg}$ at $\mathrm{H} 6, \mathrm{H} 24$ and $\mathrm{H} 48$ post-surgery).

Results: B1R inactivation helps to maintain MAP above $65 \mathrm{mmHg}$ but induces different permeability profiles depending on whether or not organ perfusion is autoregulated. In our model, VE-cadherin was destabilized in vivo during septic shock. At a late stage of sepsis, the B1R blockade reduced the VE-cadherin disruption by limiting eNOS activation. The survival rate for mice that received R-954 after sepsis induction was higher than in animals that received an antagonist as a prophylactic treatment.

Conclusions: B1R antagonizing reduced mortality in our model of murine septic shock by limiting the vascular permeability induced by VE-cadherin destabilization through maintenance of the macrohemodynamics, consequently limiting organ dysfunctions.

Keywords: Septic shock, Endothelial permeability, VE-cadherin, Kinin B1 receptor, B1R antagonist R-954

*Correspondence: ruiz.stephanie@chu-toulouse.fr

${ }^{2}$ Institute of Metabolic and Cardiovascular Diseases, INSERM/UPS UMR, 1048-I2MC, Equipe 3, Paul Sabatier University, Toulouse, France

Full list of author information is available at the end of the article

\section{Background}

Sepsis and septic shock remain leading causes of high morbimortality related to organ dysfunctions $[1,2]$. Epithelial and endothelial barriers support homeostasis and organ function by establishing gradients between each compartment [3]. In sepsis, the endothelial barrier becomes incompetent, with plasma leakage into 
interstitial tissues resulting in edema which contributes to hypovolemia and poor tissue perfusion.

The endothelium drives the host-pathogen responses by promoting inflammation, coagulation and vascular permeability, through activation of the contact-phase system and the kinin-kallikrein system. When this response is uncontrolled, organ failures occur. Kinins, released at the early stage of sepsis, induce vascular leakage and vasodilation. They act via two G-protein coupled receptors: B1 (B1R) and B2 (B2R). The constitutive B2R mediates the action of kinins immediately after a harmful stimulus during the acute phase of inflammation. B1R is inducible in the presence of pro-inflammatory cytokines, endotoxins or after tissue injury. It acts at a later stage and elicits a sustained inflammatory response [4-6].

Endothelial cohesion is ensured by an adherens junction protein, Vascular Endothelial cadherin (VEcadherin). When VE-cadherin is destabilized, the endothelium loses its barrier function. The role of this cadherin in sepsis-induced hyperpermeability has been poorly investigated in vivo in a polymicrobial sepsis model. However, studies on cell cultures or after lipopolysaccharide (LPS) challenge tend to confirm its pivotal action in the pathophysiology of endothelial dysfunction $[7,8]$. Previous studies show how difficult it is to control the regulation of the sepsis-induced inflammatory response during the initial phase. However, it would be interesting to limit the chronicization of endothelial dysfunction in order to optimize septic shock management.

With this in mind, this study investigates the effects in vivo of a B1R antagonist, the R-954, on septic hyperpermeability, VE-cadherin destabilization and survival in a later phase of polymicrobial sepsis in mice induced by cecal ligation and puncture (CLP).

\section{Methods}

\section{Animals}

The animals used in this study were 15 to 25 -week old male mice, wild-type strain C57BL/6J (WT). Animal experimentation was conducted according to national and institutional animal care and ethical guidelines and was approved by the local board. Sepsis was induced by cecal ligation and puncture (CLP) as previously described, with a cecal ligation height of $20 \%$ and a $20 \mathrm{G}$ needle [9]. Animals were anesthetized with an intraperitoneal injection of ketamine and xylazine $(250 \mathrm{mg} / \mathrm{kg}$ and $10 \mathrm{mg} / \mathrm{kg}$, respectively). Immediately post-surgery, $1 \mathrm{ml}$ of saline was administered subcutaneously for fluid resuscitation. Pain control for CLP and sham mice was achieved with $0.05 \mathrm{mg} / \mathrm{kg}$ buprenorphine every $12 \mathrm{~h}$. Mice were housed in a temperature-controlled room on a 12-h light-dark cycle and had access to water and food ad libitum.

\section{Experimental protocol}

The flow charts of the three experimental series are provided in the Additional file 1.

\section{First experimental series: role of $B 1 R$ in sepsis-induced late vascular permeability}

We first examined the influence of B1R on sepsis-induced vascular permeability of the heart, lungs, kidneys, liver and small intestine, $30 \mathrm{~h}$ after surgery, using the Evans blue dye (EBD) extravasation method $(0.5 \mathrm{~g} / 100 \mathrm{ml}$, Assistance Publique-Hôpitaux de Paris pharmacy), as previously described [10]. This timing corresponds to a "later" phase of sepsis and refers to the period following the early hyperinflammatory phase. It corresponds to a late innate immune dysfunction. In the cecal ligation and puncture model, this phase occurs at least $20 \mathrm{~h}$ after surgery in mice $[9,11]$.

The animals were divided into 3 groups: sham-operated C57BL/6J controls (WT sham; $\mathrm{n}=8$ ), CLP-induced septic C57BL/6J mice (WT CLP; $n=6$ ) and CLP-induced septic $\mathrm{C} 57 \mathrm{BL} / 6 \mathrm{~J}$ mice that received prophylactic B1R antagonist R-954 (WT CLP R-954; $\mathrm{n}=6$ ). The precise technique is described in Additional file 1. The results, calculated from a standard EBD curve (0.5-25 mg/l), are expressed in $\mu \mathrm{g}$ of Evans blue dye/g of dry tissue.

The selective B1R antagonist, R-954, was injected subcutaneously at a dose of $200 \mu \mathrm{g} / \mathrm{kg}$ prior to CLP and $24 \mathrm{~h}$ after surgery as a "prophylactic" treatment regimen (donation by R. Couture, see details in Additional file 1) [12].

Mean arterial pressure (MAP) was measured before surgery and before sacrifice $30 \mathrm{~h}$ after surgery. We anesthetized the mice in preparation for surgery. Femoral arterial pressure was monitored after a stabilization period of $5 \mathrm{~min}$ after anesthesia and every $30 \mathrm{~s}$ for $10 \mathrm{~min}$ using a blood pressure analyzer (Statham P10 EZ transducer coupled to a TA 4000; Gould, Eichstetten, Germany). Before the EBD challenge, the same protocol was used to measure the MAP on the contralateral femoral artery. The results that were published are related to the mean MAP value.

The renal expression of genes involved in inflammation (TNF- $\alpha$, IL-1 $\beta$ and IL-6), endothelial function (eNOS, iNOS, kinin B2 receptor, VEGF receptor 1 and 2) and VE-cadherin was determined $30 \mathrm{~h}$ after the initial surgery. The fragments of kidneys were stored at $-80^{\circ} \mathrm{C}$ in a stabilizing solution (RNAlater, Qiagen, Hilden, Germany) until RNA extraction. The precise techniques of mRNA extraction and reverse-transcriptase PCR are described in Additional file 1. All samples were run in duplicate, and results analyzed using SDS 2.3 software (Applied Biosystems, Thermo Fisher Scientific Inc., Waltham, 
Massachusetts). Relative mRNA expression levels were calculated with the delta-delta CT method and were normalized to GAPDH.

\section{Second experimental series: effect of B1R pharmacological blockade on VE-cadherin expression}

We studied the role of sepsis in a potential VE-cadherin destabilization in an in vivo model, and the impact of a B1R antagonist on inflammatory parameters, organ dysfunctions and VE-cadherin maintenance in two organs of interest: lungs and kidneys (WT sham $\mathrm{n}=7$; WT CLP $\mathrm{n}=11$; WT CLP R-954 $\mathrm{n}=10$ ).

\section{Third experimental series: effect of $B 1 R$ pharmacological blockade on survival}

We studied survival following CLP for WT animals $(\mathrm{n}=17)$ and WT animals that received R-954 as a "prophylactic" regimen (a subcutaneous injection of $200 \mu \mathrm{g} /$ $\mathrm{kg}$, prior to CLP and $24 \mathrm{~h}$ after surgery, $\mathrm{n}=9$ ), or as a "curative" regimen (injection of $100 \mu \mathrm{g} / \mathrm{kg}$ at H6, H24 and $\mathrm{H} 48$ post-surgery, $n=9$ ).

\section{Biological samples}

The blood samples were collected $30 \mathrm{~h}$ after surgery, under anesthesia, by cardiac puncture [13]. The serum samples obtained after centrifugation were immediately frozen at $-20{ }^{\circ} \mathrm{C}$ before being analyzed at the phenotyping department of the Toulouse Anexplo platform.

The biochemical determinations (ALP, ALT, AST, serum creatinine, serum lactates, and BUN) were carried out with the ABX Pentra 400 analyzer (Horiba ABX, Montpellier, France). Assessment of serum cytokine concentrations of IL- 6 and IL-10 was performed using the Luminex technique (LXAMSM-02 2-plex Mouse Luminex Magnetic Assay, IL6, IL10, Bio-Techne, Abingdon, United Kingdom).

\section{Histology and immunostaining}

The kidneys and lungs were harvested and fixed in formalin $10 \%$, dehydrated, and embedded in paraffin. Five-micrometer sections were stained with hematoxylin-eosin or used for immunohistochemistry.

We performed a semi-quantitative blind histological analysis for kidneys and lungs after hematoxylin-eosin staining. We quantified acute tubular necrosis lesions by the "Kidney Injury Score" and acute pulmonary lesions by the "Acute Lung Injury (ALI) score" described in Additional file 1 [14-16].

The antibodies used are described in Additional file 1. Confocal images were taken with the Confocal ZEISS LSM 510 microscope (Carl Zeiss, Jena, Germany). Immunohistochemical staining and fluorescence intensity were quantified using the FIJI distribution of the ImageJ software (version 1.51w, Wayne Rasband, National Institutes of Health, USA) [17].

\section{Statistical analysis}

Inter-group comparisons for the unmatched samples were performed using the Kruskal-Wallis non-parametric test, followed by a Dunn's test for the correction of risk inflation in multiple comparisons. For matched samples, we used the non-parametric Wilcoxon test. The log rank test was used to compare the survival rates between groups, followed by a Bonferroni correction for multiple comparisons. The mean survival times were evaluated with the Kaplan-Meier method. The analysis was performed with the GraphPad Prism software, version 6.01 for Windows (GraphPad Software, San Diego California USA). A value of $\mathrm{p}<0.05$ was considered as statistically significant. The results are expressed in median and interquartile range (IQR).

\section{Results}

The role of B1R in sepsis-induced vascular permeability MAP decreased $30 \mathrm{~h}$ after surgery in both groups who underwent CLP (Fig. 1, p < 0.05). Before surgery, the B1R blockade increased MAP (Fig. 1, p < 0.05). In the WT CLP R-954 group, CLP resulted in a lower significant decrease in MAP (Fig. 1, MAP at $30 \mathrm{~h}$ post-surgery $(\mathrm{mmHg})$; WT CLP: 50.5 \pm 26 ; WT CLP R-954: 69.7 \pm 12.1 . $\mathrm{p}<0.05$ between WT CLP vs WT CLP R-954).

The organs presented two different permeability profiles. For autoregulated organs (heart, kidneys), a

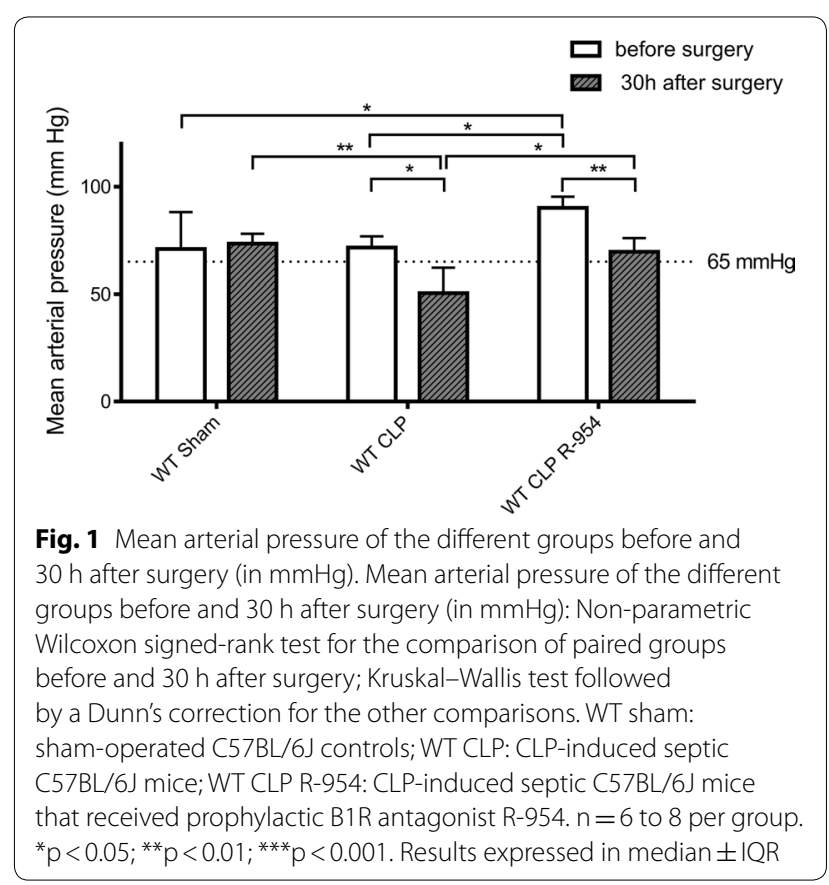


decrease in permeability was noted for the WT CLP group. The administration of a B1R antagonist prior to the induction of sepsis prevented a decrease in permeability (Fig. 2). On the other hand, we noted for the WT CLP group an increase in permeability for liver and a trend for an increased permeability for lungs during sepsis, an effect which is reduced by R-954 (Fig. 2). The lung benefited the most in terms of the effect of R-954 (Fig. 2, p $<0.05$ between WT CLP vs WT CLP R-954).
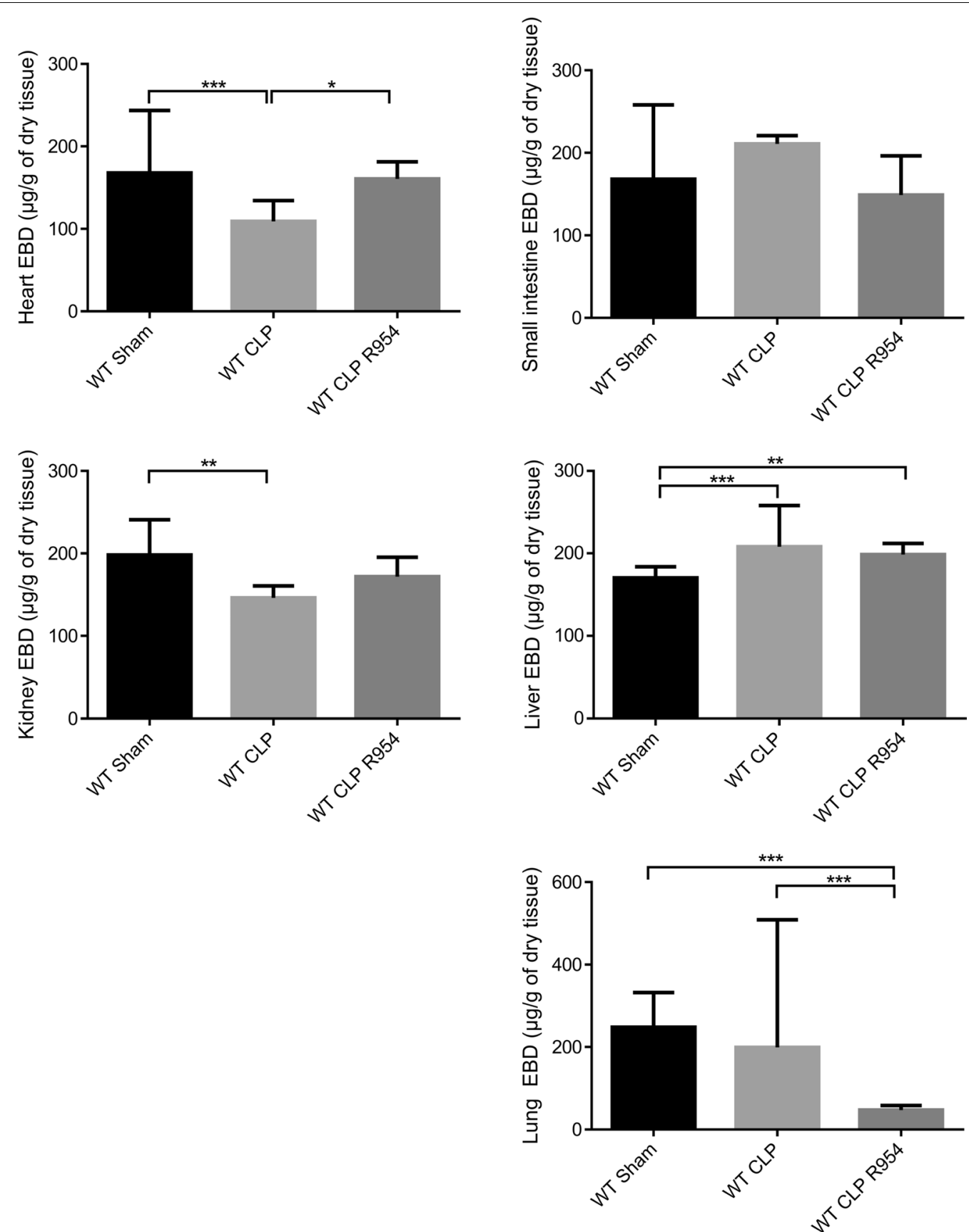

Fig. 2 Evans blue dye vascular permeability assay (in $\mu \mathrm{g} / \mathrm{g}$ of dry tissue). Evans blue dye vascular permeability assay (in $\mu \mathrm{g} / \mathrm{g}$ of dry tissue): KruskalWallis test followed by a Dunn's correction. WT sham: sham-operated C57BL/6J controls; WT CLP: CLP-induced septic C57BL/6J mice; WT CLP R-954: CLP-induced septic C57BL/6J mice that received prophylactic B1R antagonist R-954. $n=6$ to 8 per group. ${ }^{*} p<0.05 ;{ }^{* *} p<0.01 ;{ }^{* * *} p<0.001$. Results expressed in median \pm IQR 

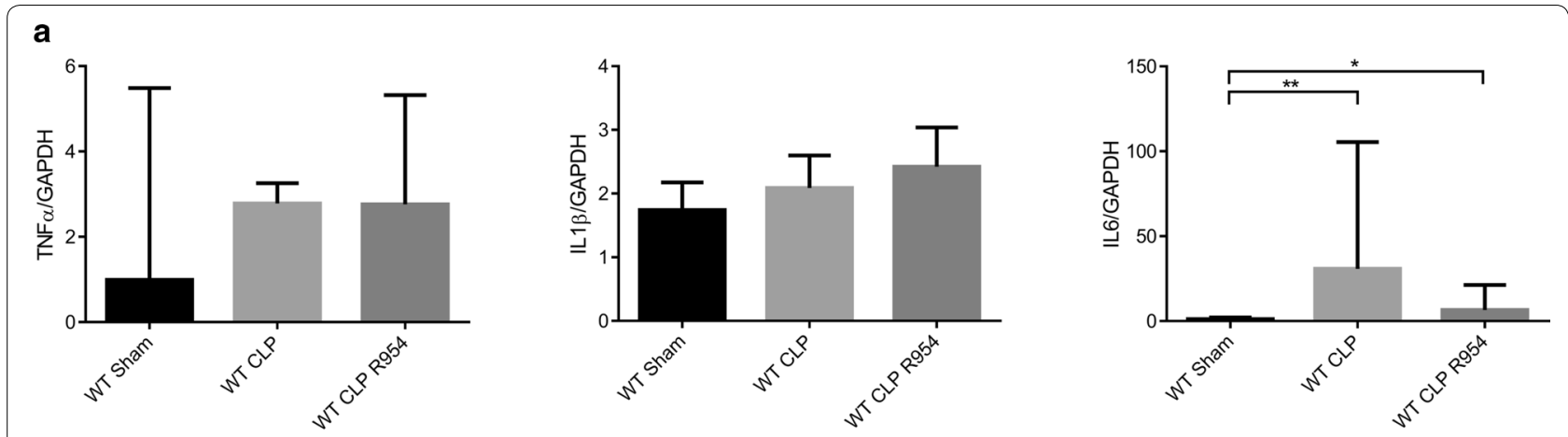

b
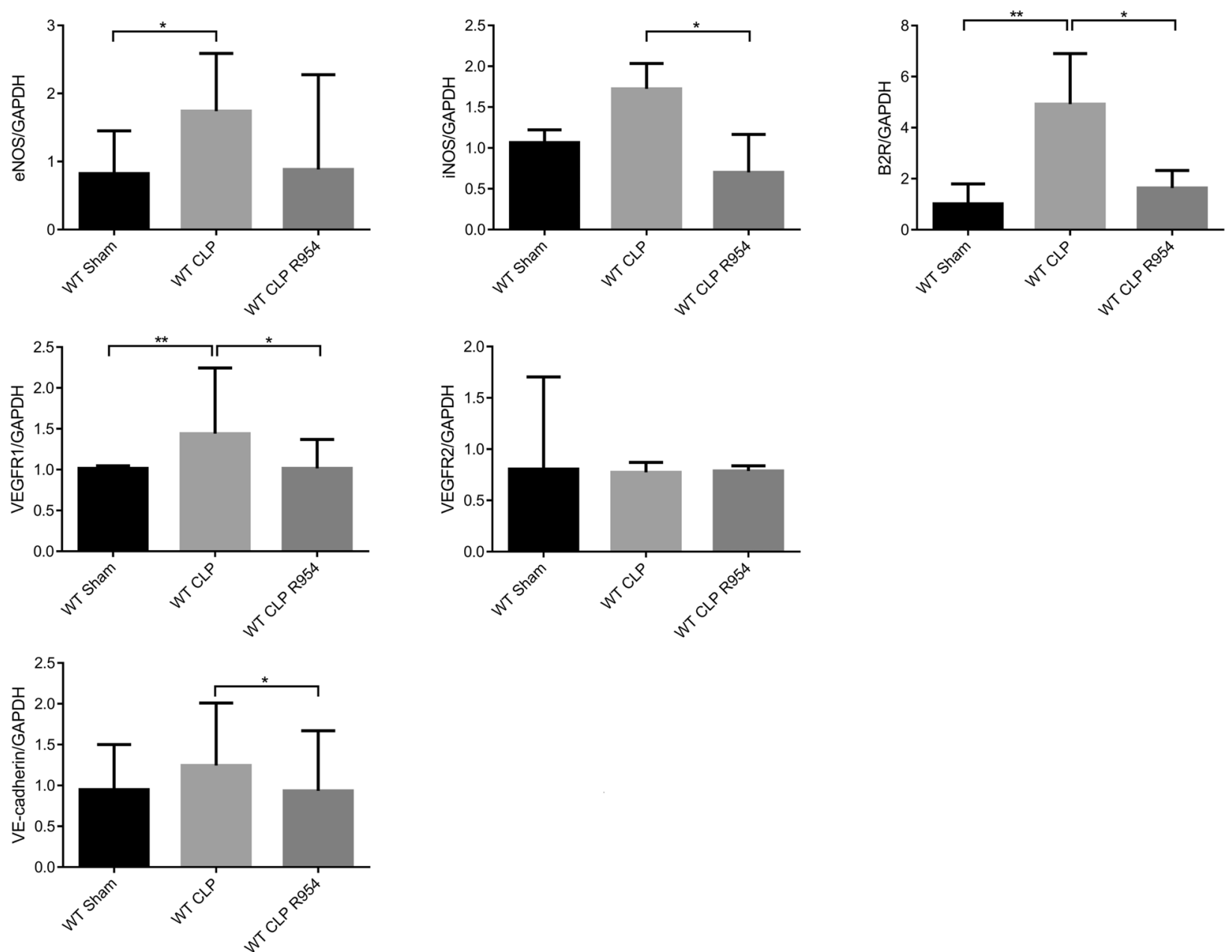

Fig. 3 Renal expression of pro-inflammatory cytokines, molecules that reflect endothelial activation and VE-cadherin. a Rt-PCR of pro-inflammatory cytokines, TNF-a, IL-1 $\beta$ and IL-6, normalized by GAPDH. b Rt-PCR of eNOS, iNOS, kinin B2 receptor, VEGFR1, VEGFR2 and VE-cadherin normalized by GAPDH. WT sham: sham-operated C57BL/6J controls; WT CLP: CLP-induced septic C57BL/6J mice; WT CLP R-954: CLP-induced septic C57BL/6J mice receiving prophylactic B1R antagonist R-954. Kruskal-Wallis test followed by a Dunn's correction. ${ }^{*} p<0.05 ;{ }^{* *} p<0.01$. Results expressed in median \pm IQR 
Renal expression of genes associated with inflammation, the function and the junctions of endothelial cells

For the kidney, only the IL-6 gene presented a significant increase in the CLP groups compared to shams (Fig. 3a).

The WT CLP group expressed more iNOS, B2R, VEGFR1 and VE-cadherin mRNAs than the WT CLP R-954 mice (Fig. 3b, p < 0.05). The eNOS expression was increased in the WT CLP group compared to the sham group (Fig. 3b).

\section{B1R blockade prevents inflammation and organ dysfunctions in septic mice}

At H30, the WT CLP R-954 group presented a more favorable anti-inflammatory balance than the WT CLP group with a higher IL-10 and a significantly lower IL-6/ IL-10 ratio (Fig. 4).

For the CLP group, we noted a significant elevation in transaminases (Fig. 5). For this group, we observed no increase in serum creatinine, while the histology confirmed the presence of significant lesions, with a Kidney Injury Score of $2.1 \pm 0.8 v s$. WT CLP R-954 with a score of $1.55 \pm 1.15$ and $v s$. shams with a score of $1.3 \pm 1$ (Figs. 5 and 6).

Similarly, the mice that received R-954 had fewer acute pulmonary lesions at $\mathrm{H} 30$ post-surgery (Fig. 7e). Their ALI score was lower than in the WT CLP mice (WT CLP R-954: $0.46 \pm 0.14$ vs. WT CLP: $0.65 \pm 0.32$, $\mathrm{p}<0.05$, Fig. 7i), and about the same as that of the sham group (WT sham: 0.41 \pm 0.18 , Fig. 7i).

\section{B1R blockade stabilizes VE-cadherin during sepsis}

For the renal cortex, VE-cadherin was significantly decreased by sepsis (mean fluorescence intensity (MFI), in the arbitrary unit (A.U.): $21.5 \pm 3.4$ for WT CLP vs. $24.6 \pm 6.6$ for WT sham $\mathrm{p}<0.0001)$. R-954 partially prevented this destabilization (22.8 A.U. \pm 6.3 for WT CLP R-954, p non-significant $v s$. WT sham and $\mathrm{p}<0.05$ vs. WT CLP) (Fig. 8a, b).

In the lungs, VE-cadherin expression was reduced for WT CLP mice in comparison to the shams (\% median expression/total surface area was respectively $20.4 \% \pm 7.1$ vs. $26.6 \% \pm 9.1, \mathrm{p}<0.0001) . \mathrm{B} 1 \mathrm{R}$ antagonizing enabled partial restoration of VE-cadherin in comparison to the WT CLP group (21.3\% \pm 5.3 for WT CLP R-954; $\mathrm{p}<0.05$ vs. WT CLP and $\mathrm{p}<0.001$ vs. WT sham) (Fig. 8c, d).

\section{B1R antagonizing limits p-eNOSser 1177 expression in the lungs during sepsis}

We paid particular attention to the expression of iNOS and p-eNOS ${ }_{\text {ser1177 }}$ isoforms in the lungs. While we found no difference in the iNOS expression at H30, the WT CLP group showed a higher level of p-eNOS (\% median expression/total surface area of $32.6 \% \pm 8.2$ for WT CLP, compared to $28.2 \% \pm 7.5$ in the shams and $25.3 \% \pm 8.4$ in WT CLP R-954) (Fig. 9).

\section{B1R blockade improves the survival of septic animals}

The survival analysis showed significant differences between the groups $(\mathrm{p}<0.005)$, with a median survival of $44 \mathrm{~h}$ for the WT CLP group. Median survival for groups that received R-954 as a "prophylaxis" or a "cure" could not be determined considering that the number of deaths was low at the end of the observation period of $96 \mathrm{~h}$ (56\% survival for the prophylactic group and $87.5 \%$ for the curative group). Only $11.8 \%$ of the mice in the WT CLP group survived at the end of the observation period. Due to the number of animals, the analysis only showed a significant difference between the WT CLP and the WT CLP R-954 curative groups (Fig. 10, p < 0.01).
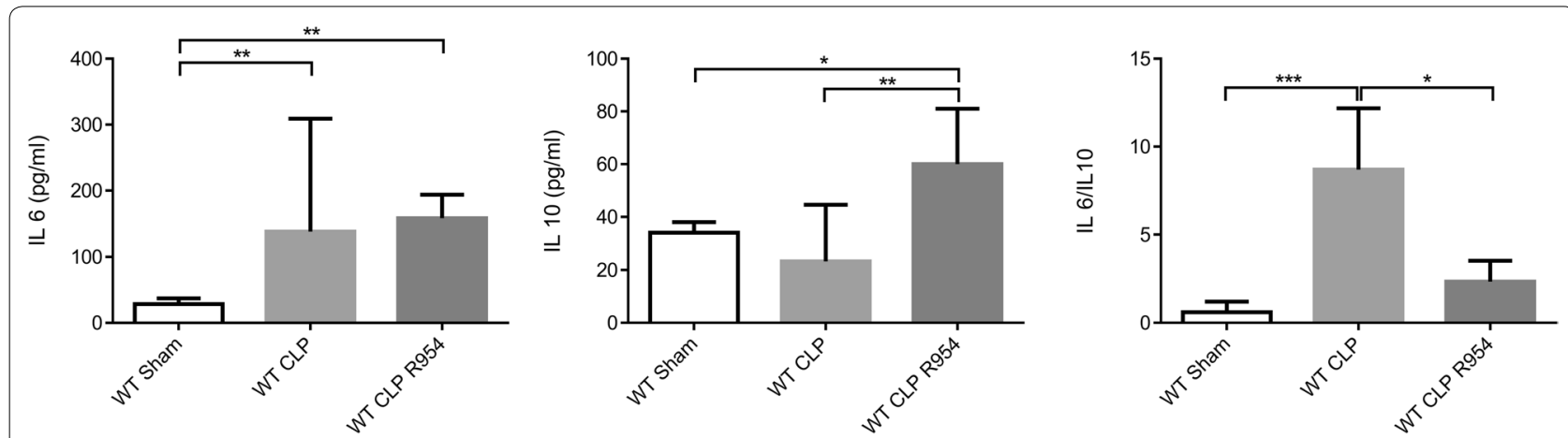

Fig. 4 The role of R1B blockade in the inflammatory profile during sepsis. Determination of the serum concentration of the pro-inflammatory cytokine, IL-6, the anti-inflammatory cytokine, IL-10 and the IL-6/IL-10 ratio at H30 post-surgery in wild-type mice. $\mathrm{n}=7$ to 11 per group. WT sham: sham-operated C57BL/6J controls; WT CLP: CLP-induced septic C57BL/6J mice; WT CLP R-954: CLP-induced septic C57BL/6J mice that received prophylactic B1R antagonist R-954. Kruskal-Wallis test followed by a Dunn's correction. ${ }^{*} p<0.05 ;{ }^{* *} p<0.01 ;{ }^{* *} p<0.001$. Results expressed in median \pm IQR 

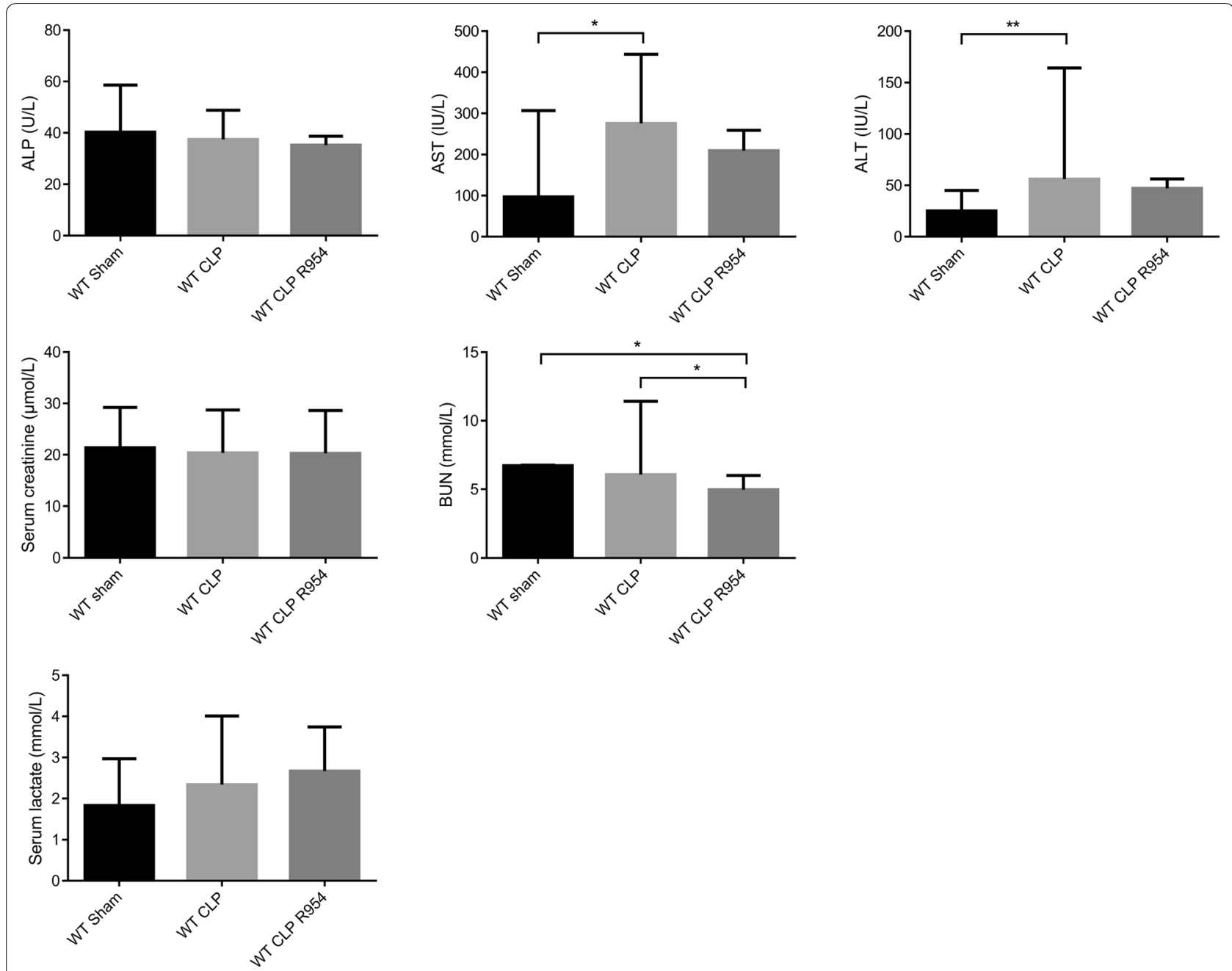

Fig. 5 The role of R1B blockade on biological markers of organ dysfunction. Determination of the serum concentration of organ dysfunction markers: liver (ALP, ASAT, ALAT), kidneys (creatinine, urea) and lactatemia, at H30 post-surgery in wild-type mice. $\mathrm{n}=7$ to 10 per group. WT sham: sham-operated C57BL/6J controls; WT CLP: CLP-induced septic C57BL/6J mice; WT CLP R-954: CLP-induced septic C57BL/6J mice receiving prophylactic B1R antagonist R-954. Kruskal-Wallis test followed by a Dunn's correction. ${ }^{*} p<0.05 ;{ }^{* *} p<0.01 ;{ }^{* * *} p<0.001$. Results expressed in median \pm IQR

\section{Discussion}

The aim of our study was to determine the involvement of B1R in sepsis-induced vascular hyperpermeability beyond the first $24 \mathrm{~h}$ of progression. To our knowledge, our study is the first to establish a connection between VE-cadherin stabilization (transmembrane component of the adherens junctions which regulate endothelial integrity), the B1R pharmacological blockade and a reduction in vascular hyperpermeability for two sepsis target organs $[18,19]$. Endothelial dysfunction was reduced, which improved the organ dysfunctions and the survival of animals that received R-954. This was consistent with two recent studies that used a B1R antagonist, BI113823, administered orally. This molecule attenuated lung injuries secondary to LPS or CLP [20, 21]. In another model of acute lung injury caused by lipopolysaccharide inhalation, R-954 counteracts the role of $B 1 R$ and prevented the airway hyperreactivity, the increased cellular infiltration and protein content in the bronchoalveolar lavage fluid, and inhibited the expression of cytokines/chemokines [22]. As was the case in these studies, we found the inflammatory profile for WT CLP R-954 mice to be less severe than for the other septic group. In fact, B1R induced NF- $\mathrm{KB}$ and therefore the production of TNF- $\alpha$ and IL-1 $\beta$, as well as CXCL5, an important mediator of neutrophil recruitment $[4,5,22-25]$. We use in our study low dose of buprenorphine $(0.05 \mathrm{mg} / \mathrm{kg}$ every $12 \mathrm{~h})$ to 

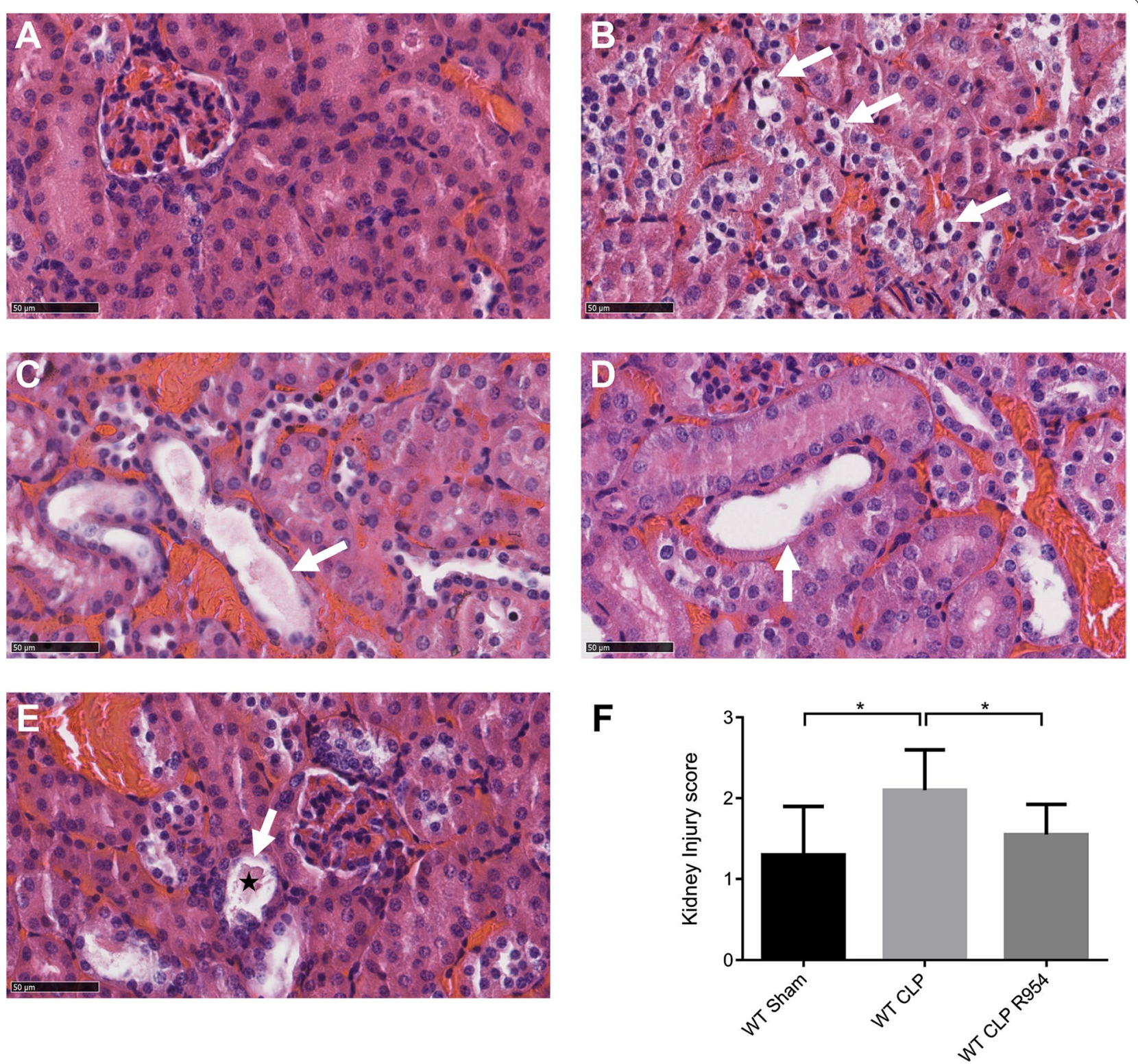

Fig. 6 The impact of R1B blockade on renal histological lesions due to sepsis. Histological analysis of the renal cortex $30 \mathrm{~h}$ after sham surgery, CLP, or CLP with R-954 antagonist. Hematoxylin-eosin staining. Magnification $\times 400$. Scale: $50 \mu \mathrm{m}$. a Normal renal parenchyma. b Renal tubular cell vacuolization lesion (white arrow). $\mathbf{c}$ Intratubular cast (white arrow). $\mathbf{d}$ Desquamation lesion (white arrow). e Example combining an intratubular cast (black star) and desquamation lesion (white arrow). $\mathbf{f}$ Mean Kidney Injury Score for 10 fields per slide evaluated in a blinded fashion (optical microscopy, ×400 magnification). WT sham: sham-operated C57BL/6J controls; WT CLP: CLP-induced septic C57BL/6J mice; WT CLP R-954:

CLP-induced septic C57BL/6J mice receiving prophylactic B1R antagonist R-954. Kruskal-Wallis test followed by a Dunn's correction. $n=7$ to 11 per group. ${ }^{*} \mathrm{p}<0.05$. Results expressed in median \pm IQR

achieve analgesia as stated by the Office of Laboratory Animal Welfare [26]. Morphine is known to increase proinflammatory mediators, however low dose of buprenorphine seems to have no effect on mortality and inflammatory response $[27,28]$. Moreover, we gave this analgesic drug to all experimental groups, hence we believe that buprenorphine is not a cofounding factor in our model. The same goes for ketamine and fluid resuscitation.

In inflammatory conditions, interendothelial cell clefts open up [29-31]. This inflammatory status was present in the WT CLP mice. $30 \mathrm{~h}$ after the beginning of sepsis, they had a serum cytokine balance that was favorable to inflammation and an increase in renal IL-6 transcription. 

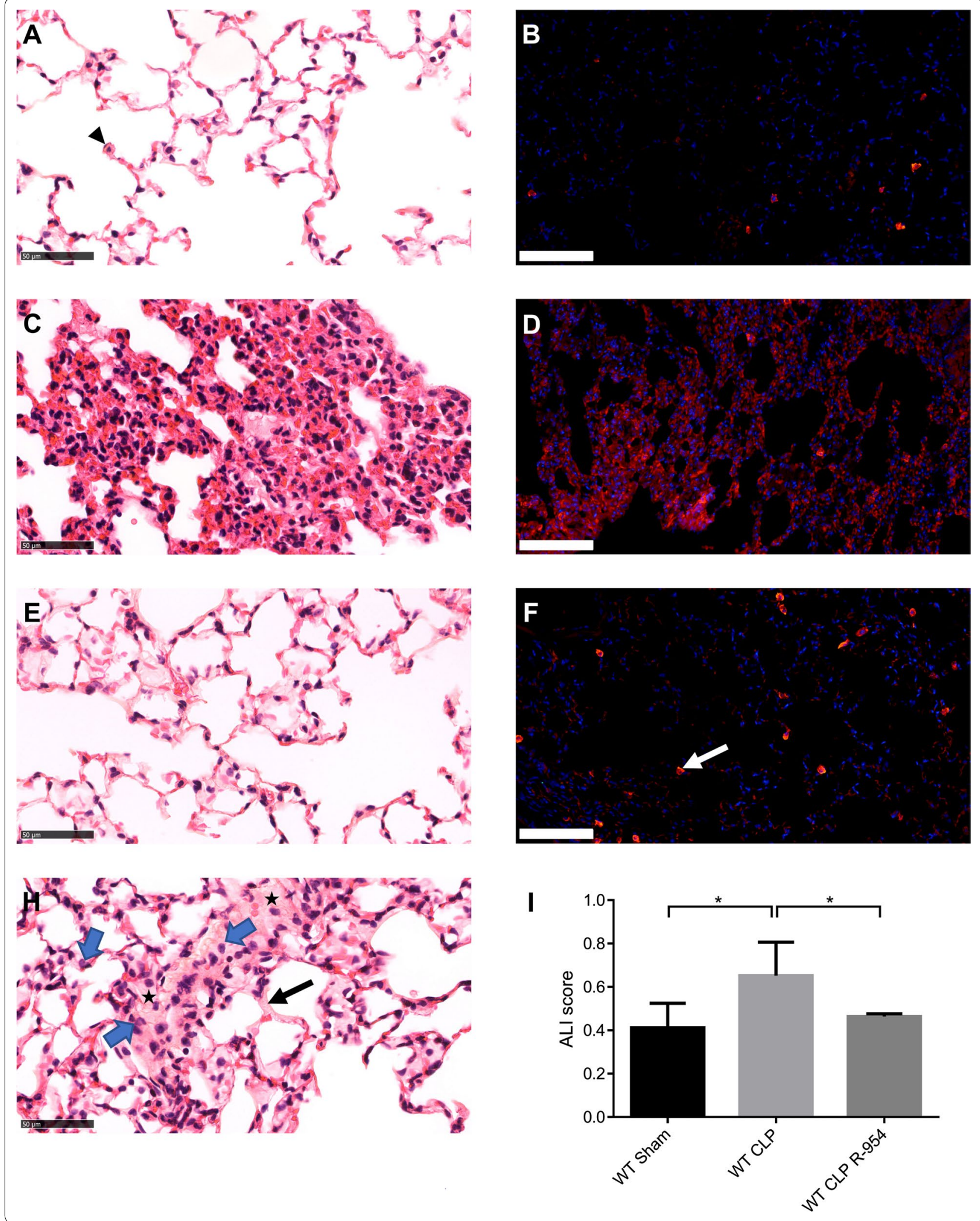
(See figure on previous page.)

Fig. 7 The impact of R1B blockade on pulmonary histological lesions due to sepsis. Pulmonary histological analysis $30 \mathrm{~h}$ after sham surgery, WT CLP, or WT CLP that received R-954 antagonist. a, c, e, $\mathbf{h}$ Hematoxylin-eosin staining. Magnification $\times 400$. Scale: 50 um. b, d, e Immunofluorescence of CD45 positive cells (panleukocyte marker) in red. Nuclei are counterstained with DAPI (blue). Magnification $\times 200$. Scale: $100 \mu \mathrm{m}$. a Pulmonary parenchyma of a sham mouse. The head of the arrow indicates an alveolar macrophage. $\mathbf{b}$ Infiltration of CD $45+$ cells in a sham mouse parenchyma. cWT CLP mouse parenchyma with acute histological pulmonary lesions characterized by alveolar septa thickening, polynuclear neutrophil infiltration and fibrin strands. $\mathbf{d}$ Infiltration of CD45 + cells in the parenchyma of a WT CLP mouse. e Pulmonary parenchyma of a WT CLP R-954 mouse. $\mathbf{f}$ Infiltration of CD45 + cells in the parenchyma of a WT CLP R-954 mouse. The white arrow indicates an alveolar macrophage. $\mathbf{g}$ Histological lesions of an acute lung injury: polynuclear neutrophils (blue arrows), intra-alveolar fibrin strands (stars), hyaline membrane (black arrow). $\mathbf{h}$ Mean Acute Lung Injury score for 5 fields per slide evaluated in a blind (optical microscopy, magnification $\times 400$ ). WT sham: sham-operated C57BL/6J controls; WT CLP: CLP-induced septic C57BL/6J mice; WT CLP R-954: CLP-induced septic C57BL/6J mice that received prophylactic B1R antagonist R-954. Kruskal-Wallis test followed by a Dunn's correction. $n=7$ to 11 per group. ${ }^{*} p<0.05$. Results expressed in median \pm IQR

While at first glance the permeability profile was different in the WT CLP group, our in vivo results concerning VE-cadherin expression confirmed AJ destabilization in two organs subjected to septic dysfunctions: the kidney (autoregulated organ) and the lung (non-autoregulated). Renal expression of the VE-cadherin gene increased in the WT CLP group while protein expression decreased. In fact, vascular permeability controlled by VE-cadherin was regulated in many ways, notably by VE-cadherin cleavage or internalization [32]. This opposite effect on mRNA and protein expression has been observed before in mice kidneys after LPS challenge, probably to compensate for loss of the protein function [33, 34].

These results should be taken into account considering the physical determinants of capillary filtration, described by the revised Starling principle [30, 35]:

$$
\mathrm{Jv}=\mathrm{Kf}[(\mathrm{Pc}-\mathrm{Pi})-\sigma(\Pi \mathrm{c}-\Pi \mathrm{g})]
$$

(Jv: fluid filtration rate, Kf: filtration coefficient, Pc: capillary hydrostatic pressure, Pi: interstitial hydrostatic pressure, $\sigma$ : reflection coefficient, Пc: capillary oncotic pressure, Пg: sub-glycocalyx oncotic pressure).

The revised law proposes that the glycocalyx acts as the effective osmotic barrier. The glycocalyx is a dynamic structure which is directly impacted by the composition of plasma and exogenous fluids. For example, albumin is particularly necessary to maintain normal myocardial microvascular permeability [36]. In kidney, fluid absorption is sustained by local epithelial secretions, which flush interstitial plasma proteins into the lymphatic system [30].
The WT CLP mice had a MAP of $50 \mathrm{~mm} \mathrm{Hg}$ which implies a decrease in capillary hydrostatic pressure (Pc). For autoregulated organs (heart, kidney), the decrease in fluid filtration rate was pronounced because the MAP was below the autoregulation threshold. For the other organs, the increase in permeability outweighed the decrease in Pc. On the contrary, an increase in MAP restored capillary hydrostatic pressure and consequently the filtration force.

The B1R blockade induces a different hemodynamic and permeability profile. It improves organ dysfunction by maintaining the organ perfusion pressure (MAP) and by stabilizing the interendothelial junctions. WT CLP R-954 mice had higher MAP than WT CLP mice. As a result, R-954 restored Pc in the heart and kidney and finally contributed to Evans Blue extravasation. A higher MAP was noted before surgery for the WT CLP R-954 group than for the others, which might correspond to an effect solely attributable to the antagonist [37]. Even if significant, the fall in MAP in this group before CLP and at $30 \mathrm{~h}$ may not be linked to sepsis, but to initial hypertension. The other organs showed a decrease in permeability in the R-954 group as reported in the literature [21, 38, 39]. Moreover, the significant decrease in extravasation of EBD in the lungs is partially explained by the action of B1R in the pulmonary vascular bed. B1 receptors have been shown to mediate strong contractile response in pulmonary arteries and likely participate in the increase of pulmonary vascular resistance [40, 41]. Inhibition of B1R attenuates this phenomenon [40]. In general, it would seem that B1R activation consistently

\footnotetext{
(See figure on next page.)

Fig. 8 VE-cadherin expression in the renal cortex and lungs. a VE-cadherin immunostaining in the renal cortex of the WT sham, WT CLP and WT CLP R-954 groups. Specific fluorescence: green for VE-cadherin, orange for isolectin B4 (endothelial cell marker), blue for cell nuclei (DAPI). Scale: $50 \mu m$. b Mean fluorescence intensity established for 10 fields selected randomly by slide, magnification $\times 400$. A.U.: arbitrary unit; $n=7$ to 11 per group. c VE-cadherin immunostaining in the lungs of the WT sham, WT CLP and WT CLP R-954 groups. Scale: $50 \mu \mathrm{m}$ (optical microscope magnification $\times 400)$. $\mathbf{d}$ VE-cadherin expression in relation to the total immunostained surface area, established for 10 fields selected randomly by slide, with magnification $\times 400$ (in \%); $n=7$ to 10 per group. WT sham: sham-operated C57BL/6J controls; WT CLP: CLP-induced septic C57BL/6J mice; WT CLP R-954: CLP-induced septic C57BL/6J mice that received prophylactic B1R antagonist R-954. Kruskal-Wallis test followed by a Dunn's correction ${ }^{*} \mathrm{p}<0.05 ;{ }^{* * *} \mathrm{p}<0.001 ;{ }^{* * *} \mathrm{p}<0.0001$. Results expressed in median $\pm \mathrm{IQR}$
} 

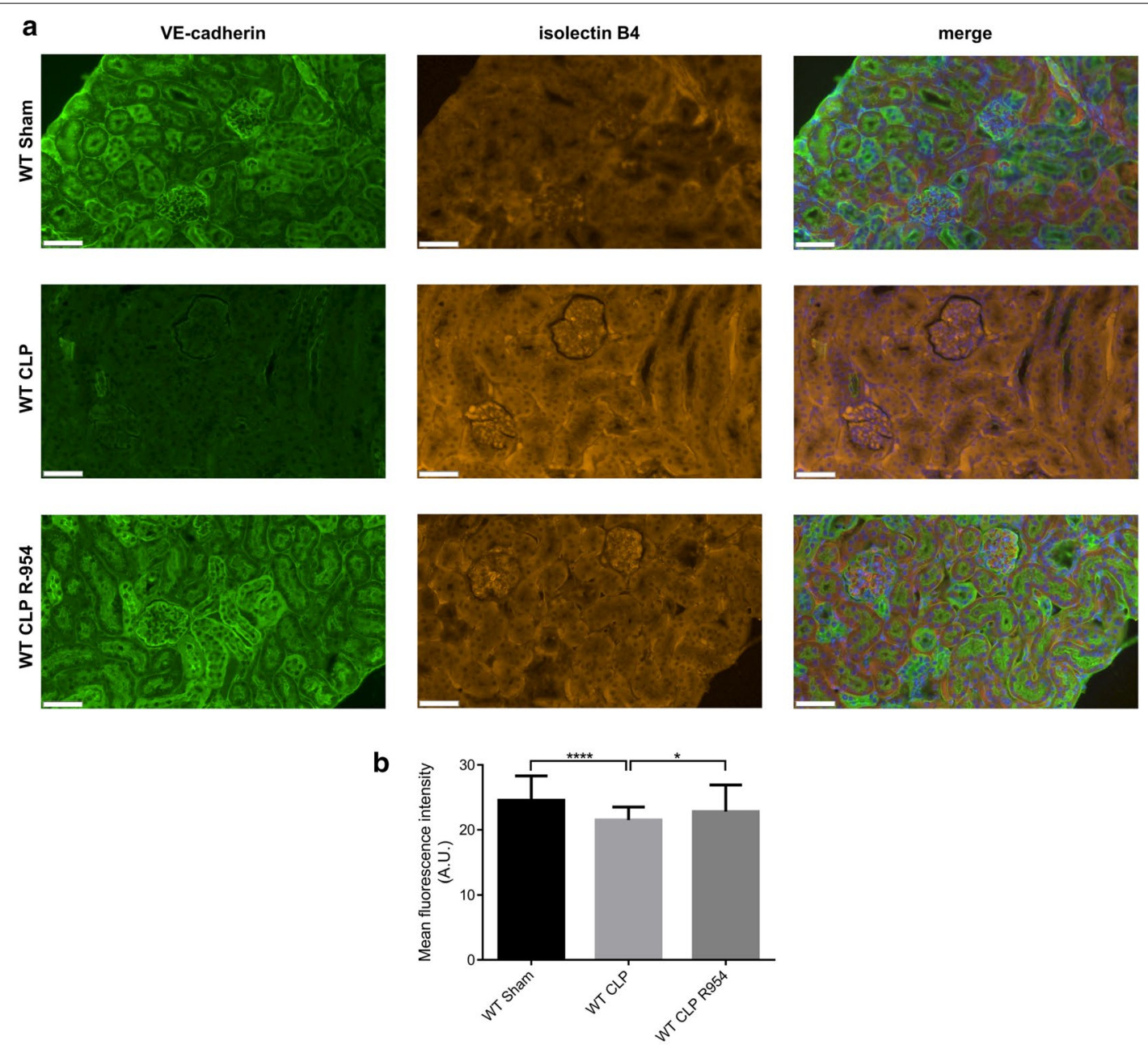

C
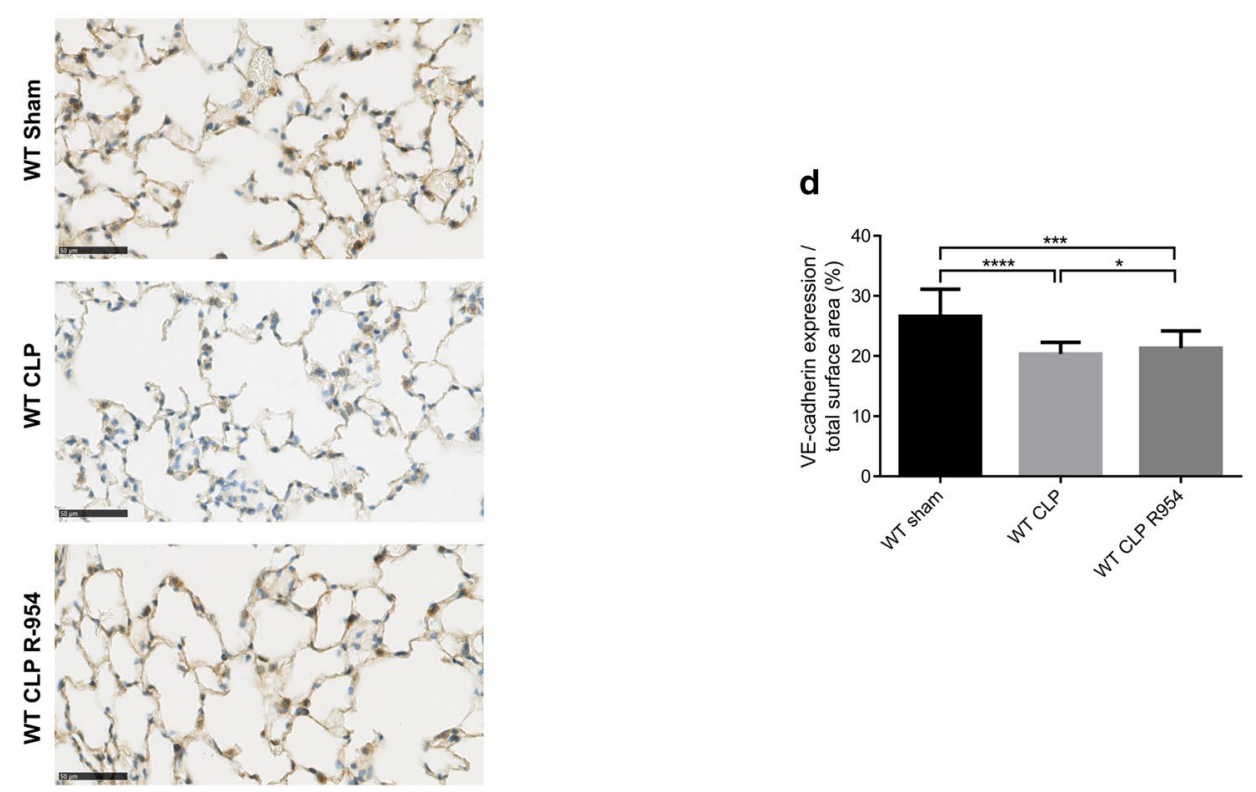


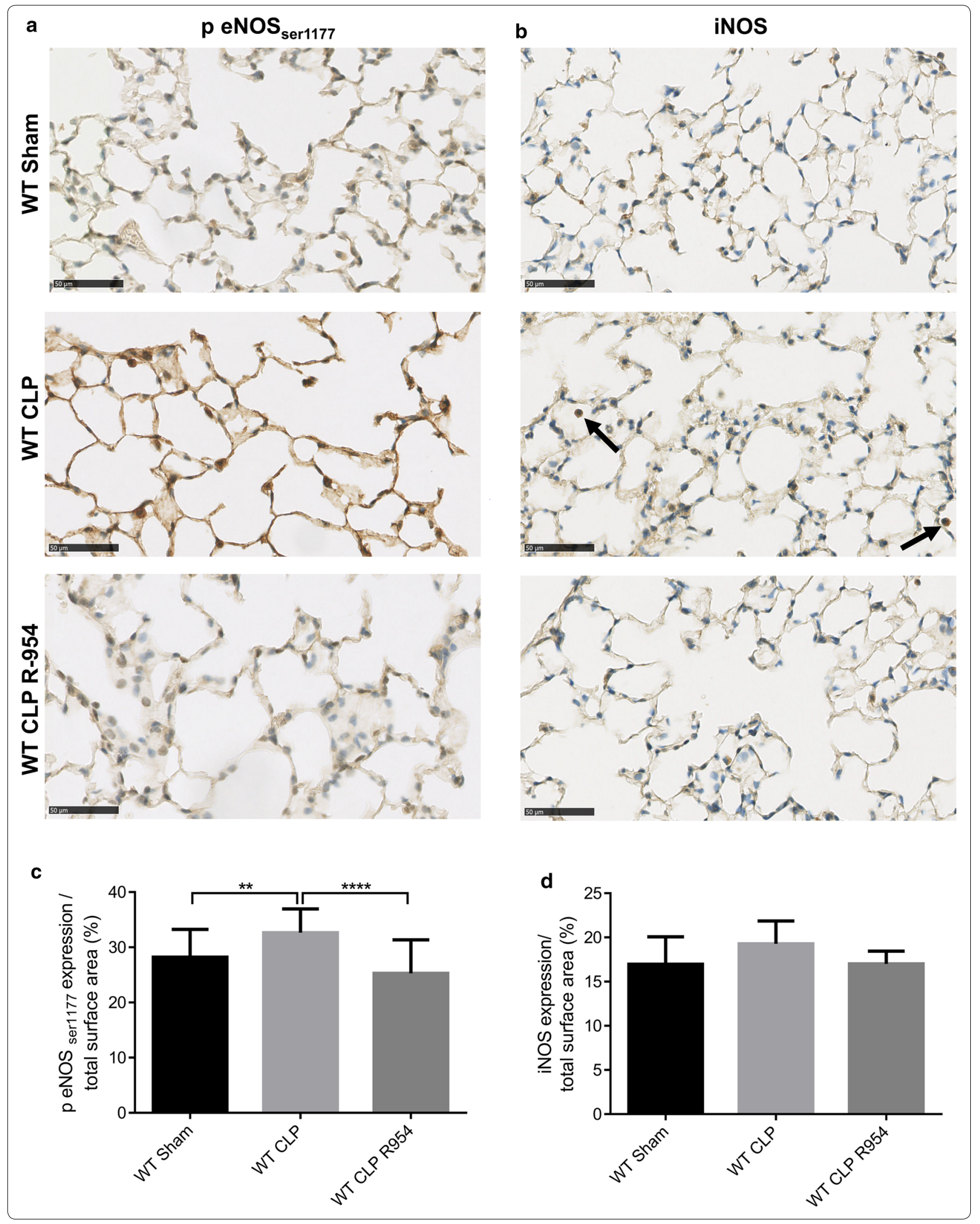


(See figure on previous page.)

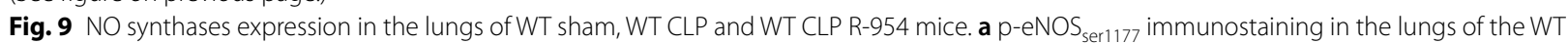
sham, WT CLP and WT CLP R-954 groups. Scale: $50 \mu \mathrm{m}$ (optical microscope magnification $\times 400$ ). $\mathbf{b}$ iNOS immunostaining in the lungs of the WT sham, WT CLP and WT CLP R-954 groups. The black arrows indicate intra-alveolar macrophages marked by iNOS. Scale: 50 um (optical microscope magnification $\times 400$ ). c p-eNOS ${ }_{\text {ser } 1177}$ expression in relation to the immunostained total surface area, established for 10 fields selected randomly by slide, with magnification $\times 400$ (in \%). (D) iNOS expression in relation to the immunostained total surface area, established for 10 fields selected randomly by slide, with magnification $\times 400$ (in \%). WT sham: sham-operated C57BL/6J controls; WT CLP: CLP-induced septic C57BL/6J mice; WT CLP R-954: CLP-induced septic C57BL/6J mice receiving prophylactic B1R antagonist R-954. For $\mathbf{c}$ and $\mathbf{d}$ Kruskal-Wallis test followed by a Dunn's correction. $n=7$ to 10 per group. ${ }^{* *} p<0.01 ;{ }^{* * *} p<0.0001$. Results expressed in median $\pm I Q R$

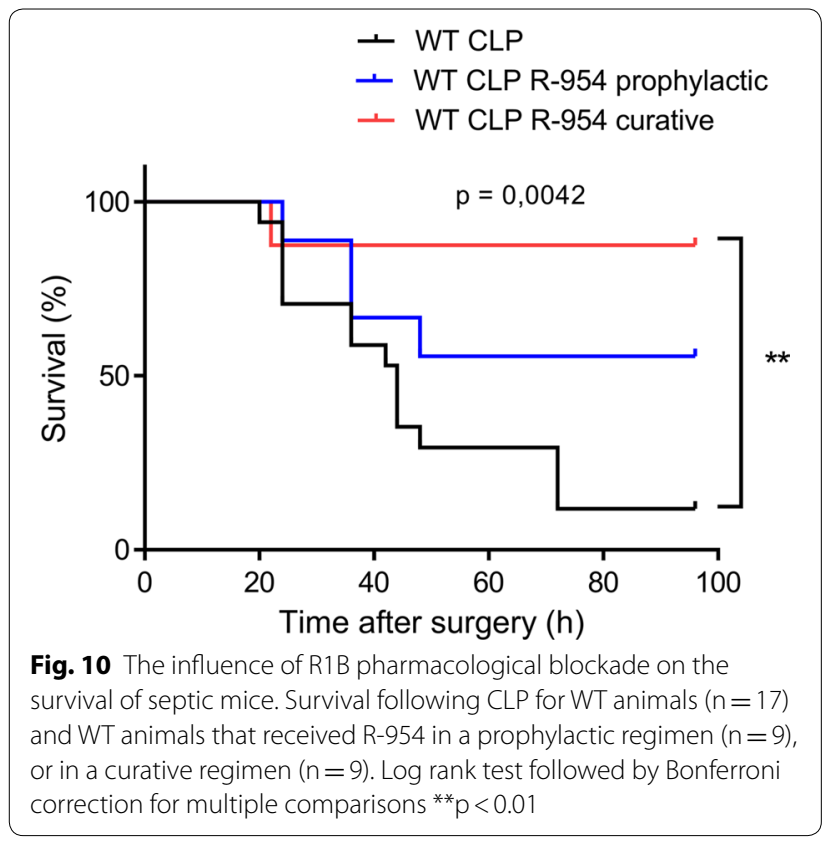

produces vasoconstriction in veins and vasodilatation in arteries [42]. Studies suggest that central B1R may play a role in the pathology of essential hypertension. However normal regulation of arterial pressure does not appear to involve this receptor since $\mathrm{B} 1 \mathrm{R} \mathrm{KO}$ mice display a normal phenotype $[43,44]$.

VE-cadherin is the target of a plethora of signaling pathways, which can lead to a break in the endothelial barrier. We paid particular attention to the NO pathways, known to induce vascular hyperpermeability, especially since kinin receptors activate eNOS and iNOS. eNOS derived-NO is considered to be beneficial in the vessel wall because this enzyme produces appropriate amounts of NO, unlike the high NO output generated by iNOS [45-47]. We found no iNOS staining in the lung at a late phase after surgery, but a p-eNOS ${ }_{\text {ser1177 }}$ overexpression in WT CLP mice in comparison to the group that received the antagonist. This form is known to lead to VE-cadherin destabilization by enabling phosphorylation and S-nitrosylation of this cadherin and its partner proteins [18, 48-50]. Moreover, in an inflammatory endothelium, eNOS is capable of producing amounts of NO that are identical to iNOS for extended periods $[47,51]$.

In a similar manner to the different permeability patterns, the mice with blocked B1R did not have the same NOS expression profile as the WT mice. What was surprising at first glance was the difference in eNOS expression between the two septic groups, WT CLP and WT CLP R-954, whether it concerned the renal transcription or the activated protein form in the lung. Actually, B2R is reputed to be an eNOS activator, but $\mathrm{B} 1 \mathrm{R}$ is also capable of similar effects because these two receptors share the same signaling pathways [4-6]. Various researches have shown either negative regulation of eNOS transcription in the absence of B1R, a co-localization of B1R and eNOS, or new potential transduction pathways that enable the activation of eNOS by B1R [52-55]. In addition, B1R is capable of activating the PI3/Akt pathway, which phosphorylates eNOS in serine 1177 [56-58].

B1R blockade improved the survival of septic animals only in the group receiving treatment after induction of sepsis. Mice receiving treatment before CLP, however, seem to survive better than septic mice without any treatment. The lack of significance can be explained by an insufficient number of animals in this experimental group. The more favorable profile of survival in the group receiving R-954 after CLP emphasizes the Janus-faced aspect of B1R. B1R enables the transmigration of neutrophils to inflammatory sites by causing the overexpression of the chemokine CXCL5 on the surface of endothelial cells [59]. Therefore, blocking it immediately could limit an immune response favorable to the elimination of the pathogen. The following two notions can be derived from this result: it is continuous and deregulated stimulation of B1R that is harmful and a B1R antagonist might therefore have a place in the armamentarium against septic shock because the action also seems more favorable when the inflammatory response is already initiated. 


\section{Conclusions}

B1R blockade promotes the anti-inflammatory balance and improves the hemodynamics and the maintenance of VE-cadherin by limiting the activation of eNOS. This pharmacological blockade has a greater protective effect after the induction of sepsis. The antagonist that we used, R-954, authorized for a phase 1 study in humans by Health Canada, could provide a promising new therapeutic strategy for septic shock management.

\section{Supplementary information}

Supplementary information accompanies this paper at https://doi. org/10.1186/s12967-020-02342-8.

Additional file 1. Materials and methods.

\section{Abbreviations}

ALI: Acute lung injury; B1R: Kinin B1 receptor; B2R: Kinin B2 receptor; CLP: Cecal ligation and puncture; EBD: Evans blue dye; Jv: Fluid filtration rate; Kf: Filtration coefficient; LPS: Lipopolysaccharide; MAP: Mean arterial pressure; MFI: Mean fluorescence intensity; PC: Capillary hydrostatic pressure; Pi: Interstitial hydrostatic pressure; VE-cadherin: Vascular endothelial cadherin; WT: Wild type; Пc: Capillary oncotic pressure; $\Pi g$ : Sub-glycocalyx oncotic pressure; $\sigma$ : Reflection coefficient.

\section{Acknowledgements}

We would like to thank Marie Cauquil for her kind help with immunofluorescence analysis, Rémy Flores-Flores (TRI-GENOTOUL Cell Imagery Platform, I2MC) for his help with the ImageJ macros design and Della Hoy for her kind help in proofreading English.

\section{Authors' contributions}

Conception and design of the experiments: SR, CG-F and IT. Carrying out the experiments: SR, FV-B, MB and MHS. Data analysis: SR, VM and JMC. Writing the paper: SR, JPG, VM, and IT. All authors read and approved the final manuscript.

\section{Funding}

The selective kinin B1 receptor antagonist, R-954, was donated by Réjean Couture (Département de Pharmacologie et Physiologie, Université de Montréal, Montréal, QC, Canada). Other support was provided solely from institutional and/or departmental sources.

\section{Availability of data and materials}

The datasets used and/or analysed during the current study are available from the corresponding author on reasonable request.

\section{Ethics approval and consent to participate}

Animal experimentation was performed according to national and institutional animal care and ethical guidelines and was approved by the local board.

\section{Consent for publication}

Not applicable.

\section{Competing interests}

The authors declare that they have no conflicts of interests.

\footnotetext{
Author details

${ }^{1}$ Department of Anesthesiology and Intensive Care, Rangueil HospitalUniversity Hospital of Toulouse, 1 Avenue du Professeur Jean Poulhès TSA 50032, 31059 Toulouse Cedex 9, France. ${ }^{2}$ Institute of Metabolic and Cardiovascular Diseases, INSERM/UPS UMR, 1048-I2MC, Equipe 3, Paul Sabatier University, Toulouse, France. ${ }^{3}$ Department of Forensic Medicine, Rangueil Hospital-University Hospital of Toulouse, 1 Avenue du Professeur Jean Poulhès TSA 50032, 31059 Toulouse Cedex 9, France. ${ }^{4}$ Biological Electron Microscopy Center, Rangueil Faculty of Medicine, Toulouse University, Toulouse, France.
}

${ }^{5}$ Department of Physiology, Rangueil Hospital-University Hospital of Toulouse, 1 Avenue du Professeur Jean Poulhès TSA 50032, 31059 Toulouse Cedex 9. France.

Received: 5 December 2019 Accepted: 10 April 2020

Published online: 19 April 2020

\section{References}

1. Fleischmann C, Scherag A, Adhikari NK, Hartog CS, Tsaganos T, Schlattmann P, Angus DC, Reinhart K, International Forum of Acute Care T. Assessment of global incidence and mortality of hospital-treated sepsis current estimates and limitations. Am J Respir Crit Care Med. 2016;193:259-72

2. Vincent JL, Sakr Y, Sprung CL, Ranieri VM, Reinhart K, Gerlach H, Moreno R, Carlet J, Le Gall JR, Payen D. Sepsis occurrence in acutely ill patients I: sepsis in European intensive care units: results of the SOAP study. Crit Care Med. 2006;34:344-53.

3. Deutschman CS, Tracey KJ. Sepsis: current dogma and new perspectives. Immunity. 2014;40:463-75.

4. Leeb-Lundberg LM. Kinin receptor signaling and regulation. In: Bader M, editor. Kinins. Berlin, Boston: De Gruyter; 2011. p. 33-50.

5. Leeb-Lundberg LM, Marceau F, Muller-Esterl W, Pettibone DJ, Zuraw BL. International union of pharmacology. XLV. Classification of the kinin receptor family: from molecular mechanisms to pathophysiological consequences. Pharmacol Rev. 2005;57:27-77.

6. Moreau ME, Garbacki N, Molinaro G, Brown NJ, Marceau F, Adam A. The kallikrein-kinin system: current and future pharmacological targets. J Pharmacol Sci. 2005;99:6-38.

7. Yan Z, Wang ZG, Segev N, Hu S, Minshall RD, Dull RO, Zhang M, Malik $A B, H u$ G. Rab1 1 a mediates vascular endothelial-cadherin recycling and controls endothelial barrier function. Arterioscler Thromb Vasc Biol. 2016;36:339-49.

8. London NR, Zhu W, Bozza FA, Smith MC, Greif DM, Sorensen LK, Chen L, Kaminoh Y, Chan AC, Passi SF, et al. Targeting Robo4-dependent Slit signalling to survive the cytokine storm in sepsis and influenza. Sci Transl Med. 2010;2:23ra19.

9. Ruiz S, Vardon-Bounes F, Merlet-Dupuy V, Conil JM, Buleon M, Fourcade $\mathrm{O}$, Tack I, Minville V. Sepsis modeling in mice: ligation length is a major severity factor in cecal ligation and puncture. Intensive Care Med Exp. 2016;4:22.

10. Rogers DF, Boschetto P, Barnes PJ. Plasma exudation Correlation between Evans blue dye and radiolabeled albumin in guinea pig airways in vivo. J Pharmacol Methods. 1989;21:309-15.

11. Cauvi DM, Song D, Vazquez DE, Hawisher D, Bermudez JA, Williams MR, Bickler S, Coimbra R, De Maio A. Period of irreversible therapeutic intervention during sepsis correlates with phase of innate immune dysfunction. J Biol Chem. 2012;287:19804-15.

12. Neugebauer W, Blais PA, Halle S, Filteau C, Regoli D, Gobeil F Jr. Kinin B1 receptor antagonists with multi-enzymatic resistance properties. Can J Physiol Pharmacol. 2002;80:287-92.

13. Singleton KD, Wischmeyer PE. Distance of cecum ligated influences mortality, tumor necrosis factor-alpha and interleukin-6 expression following cecal ligation and puncture in the rat. Eur Surg Res. 2003;35:486-91.

14. Mayeur N, Minville V, Jaafar A, Allard J, Al Saati T, Guilbeau-Frugier C, Fourcade O, Girolami JP, Schaak S, Tack I. Morphologic and functional renal impact of acute kidney injury after prolonged hemorrhagic shock in mice. Crit Care Med. 2011;39:2131-8.

15. Melnikov VY, Faubel S, Siegmund B, Lucia MS, Ljubanovic D, Edelstein CL. Neutrophil-independent mechanisms of caspase-1- and IL-18-mediated ischemic acute tubular necrosis in mice. J Clin Invest. 2002:110:1083-91.

16. Matute-Bello G, Downey G, Moore BB, Groshong SD, Matthay MA, Slutsky AS, Kuebler WM. Acute Lung Injury in Animals Study G: an official American Thoracic Society workshop report: features and measurements of experimental acute lung injury in animals. Am J Respir Cell Mol Biol. 2011;44:725-38. 
17. Schindelin J, Arganda-Carreras I, Frise E, Kaynig V, Longair M, Pietzsch T, Preibisch S, Rueden C, Saalfeld S, Schmid B, et al. Fiji: an open-source platform for biological-image analysis. Nat Methods. 2012;9:676-82.

18. Komarova YA, Kruse K, Mehta D, Malik AB. Protein interactions at endothelial junctions and signaling mechanisms regulating endothelial permeability. Circ Res. 2017;120:179-206.

19. Mehta $D$, Malik AB. Signaling mechanisms regulating endothelial permeability. Physiol Rev. 2006;86:279-367.

20. Murugesan $P$, Jung B, Lee D, Khang G, Doods H, Wu D. Kinin B1 receptor inhibition with Bl113823 reduces inflammatory response, mitigates organ injury, and improves survival among rats with severe sepsis. J Infect Dis. 2016:213:532-40.

21. Nasseri S, Gurusamy M, Jung B, Lee D, Khang G, Doods H, Wu D. Kinin B1 receptor antagonist Bl113823 reduces acute lung injury. Crit Care Med. 2015;43:e499-507.

22. Campanholle G, Landgraf RG, Borducchi E, Semedo P, Wang PH, Amano MT, Russo M, Pacheco-Silva A, Jancar S, Camara NO. Bradykinin inducible receptor is essential to lipopolysaccharide-induced acute lung injury in mice. Eur J Pharmacol. 2010;634:132-7.

23. Wang PH, Campanholle G, Cenedeze MA, Feitoza CQ, Goncalves GM, Landgraf RG, Jancar S, Pesquero JB, Pacheco-Silva A, Camara NO. Bradykinin [corrected] B1 receptor antagonism is beneficial in renal ischemiareperfusion injury. PLoS ONE. 2008;3:e3050.

24. Schanstra JP, Bataillé E, Marin Castaño ME, Barascud Y, Hirtz C, Pesquero JB, Pecher C, Gauthier F, Girolami JP, Bascands JL. The B1-agonist [desArg10]-kallidin activates transcription factor NF-kappaB and induces homologous upregulation of the bradykinin B1-receptor in cultured human lung fibroblasts. J Clin Investig. 1998;101:2080-91.

25. Bascands JL, Bachvarova M, Neau E, Schanstra JP, Bachvarov D. Molecular determinants of LPS-induced acute renal inflammation: implication of the kinin B1 receptor. Biochem Biophys Res Commun. 2009;386:407-12.

26. Welfare OoLA. Public Health Service policy on humane care and use of laboratory animals. (Services DoHaH ed. Bethesda (MD); 2015.

27. Cotroneo TM, Hugunin KM, Shuster KA, Hwang HJ, Kakaraparthi BN, Nemzek-Hamlin JA. Effects of buprenorphine on a cecal ligation and puncture model in C57BL/6 mice. J Am Assoc Lab Anim Sci. 2012;51:357-65.

28. Odunayo A, Dodam JR, Kerl ME, DeClue AE. Immunomodulatory effects of opioids. J Vet Emerg Crit Care. 2010;20:376-85.

29. Kottke MA, Walters TJ. Where's the leak in vascular barriers? A Review. Shock. 2016:46:20-36.

30. Levick JR, Michel CC. Microvascular fluid exchange and the revised Starling principle. Cardiovasc Res. 2010;87:198-210.

31. Radeva MY, Waschke J (2018) Mind the gap: mechanisms regulating the endothelial barrier. Acta Physiol (Oxf). https://doi.org/10.1111/ apha.12860

32. Gavard J. Endothelial permeability and VE-cadherin: a wacky comradeship. Cell Adhes Migr. 2014;8:158-64.

33. Aslan A, van Meurs M, Moser J, Popa ER, Jongman RM, Zwiers PJ, Molema G, Zijlstra JG. Organ-specific differences in endothelial permeability-regulating molecular responses in mouse and human sepsis. Shock. 2017;48:69-77.

34. Cowan CE, Kohler EE, Dugan TA, Mirza MK, Malik AB, Wary KK. Kruppellike factor-4 transcriptionally regulates VE-cadherin expression and endothelial barrier function. Circ Res. 2010;107:959-66.

35. Woodcock TM, Woodcock TE. Revised Starling equation predicts pulmonary edema formation during fluid loading in the critically ill with presumed hypovolemia. Crit Care Med. 2012;40:2741-2 (author reply 2742).

36. Jacob M, Bruegger D, Rehm M, Stoeckelhuber M, Welsch U, Conzen P, Becker BF. The endothelial glycocalyx affords compatibility of Starling's principle and high cardiac interstitial albumin levels. Cardiovasc Res. 2007;73:575-86.

37. Gobeil F Jr, Sirois P, Regoli D. Preclinical pharmacology, metabolic stability, pharmacokinetics and toxicology of the peptidic kinin B1 receptor antagonist R-954. Peptides. 2014;52:82-9.

38. Simard B, Gabra BH, Sirois P. Inhibitory effect of a novel bradykinin B1 receptor antagonist, R-954, on enhanced vascular permeability in type 1 diabetic mice. Can J Physiol Pharmacol. 2002;80:1203-7.
39. Lawson SR, Gabra BH, Nantel F, Battistini B, Sirois P. Effects of a selective bradykinin B1 receptor antagonist on increased plasma extravasation in streptozotocin-induced diabetic rats: distinct vasculopathic profile of major key organs. Eur J Pharmacol. 2005;514:69-78.

40. Murugesan P, Hildebrandt T, Bernlohr C, Lee D, Khang G, Doods H, Wu D. Inhibition of kinin B1 receptors attenuates pulmonary hypertension and vascular remodeling. Hypertension. 2015;66:906-12.

41. Whitehurst RM, Laskey R, Goldberg RN, Herbert D, Van Breemen C. Influence of group B streptococci on piglet pulmonary artery response to bradykinin. J Appl Physiol. 1985;1999(86):61-5.

42. McLean PG, Perretti M, Ahluwalia A. Kinin B(1) receptors and the cardiovascular system: regulation of expression and function. Cardiovasc Res. 2000;48:194-210.

43. De Brito Gariepy H, Carayon P, Ferrari B, Couture R. Contribution of the central dopaminergic system in the anti-hypertensive effect of kinin B1 receptor antagonists in two rat models of hypertension. Neuropeptides. 2010;44:191-8.

44. Pesquero JB, Araujo RC, Heppenstall PA, Stucky CL, Silva JA Jr, Walther T, Oliveira SM, Pesquero JL, Paiva AC, Calixto JB, et al. Hypoalgesia and altered inflammatory responses in mice lacking kinin $B 1$ receptors. Proc Natl Acad Sci USA. 2000;97:8140-5.

45. Vincent JL, Zhang $H$, Szabo C, Preiser JC. Effects of nitric oxide in septic shock. Am J Respir Crit Care Med. 2000;161:1781-5.

46. Kathiresan S, Larson MG, Vasan RS, Guo CY, Vita JA, Mitchell GF, Keyes MJ, Newton-Cheh C, Musone SL, Lochner AL, et al. Common genetic variation at the endothelial nitric oxide synthase locus and relations to brachial artery vasodilator function in the community. Circulation. 2005;112:1419-27.

47. Forstermann $U$, Sessa WC. Nitric oxide synthases: regulation and function. Eur Heart J. 2012;33(829-837):837a-837d.

48. Di Lorenzo A, Lin MI, Murata T, Landskroner-Eiger S, Schleicher M, Kothiya M, Iwakiri Y, Yu J, Huang PL, Sessa WC. eNOS-derived nitric oxide regulates endothelial barrier function through VE-cadherin and Rho GTPases. J Cell Sci. 2013;126:5541-52.

49. Guequen A, Carrasco R, Zamorano P, Rebolledo L, Burboa P, Sarmiento J, Boric MP, Korayem A, Duran WN, Sanchez FA. S-nitrosylation regulates VE-cadherin phosphorylation and internalization in microvascular permeability. Am J Physiol Heart Circ Physiol. 2016;310:H1039-44.

50. Sanchez FA, Rana R, Kim DD, Iwahashi T, Zheng R, Lal BK, Gordon DM, Meininger CJ, Duran WN. Internalization of eNOS and NO delivery to subcellular targets determine agonist-induced hyperpermeability. Proc Natl Acad Sci USA. 2009;106:6849-53.

51. Lowry JL, Brovkovych V, Zhang Y, Skidgel RA. Endothelial nitric-oxide synthase activation generates an inducible nitric-oxide synthaselike output of nitric oxide in inflamed endothelium. J Biol Chem. 2013;288:4174-93.

52. Lauton-Santos $S$, Guatimosim S, Castro CH, Oliveira FA, Almeida AP, Dias-Peixoto MF, Gomes MA, Pessoa P, Pesquero JL, Pesquero JB, et al. Kinin $B 1$ receptor participates in the control of cardiac function in mice. Life Sci. 2007;81:814-22.

53. Ignjatovic T, Stanisavljevic S, Brovkovych V, Skidgel RA, Erdos EG. Kinin $B 1$ receptors stimulate nitric oxide production in endothelial cells: signaling pathways activated by angiotensin I-converting enzyme inhibitors and peptide ligands. Mol Pharmacol. 2004;66:1310-6.

54. Mesquita TRR, Campos-Mota GP, Lemos VS, Cruz JS, de Jesus ICG, Camargo EA, Pesquero JL, Pesquero JB, Capettini L, Lauton-Santos S. Vascular kinin B1 and B2 receptors determine endothelial dysfunction through neuronal nitric oxide synthase. Front Physiol. 2017;8:228.

55. Bai B, Liu L, Zhang N, Wang C, Jiang Y, Chen J. Heterodimerization of human apelin and bradykinin 1 receptors: novel signal transduction characteristics. Cell Signal. 2014;26:1549-59.

56. Nicoletti NF, Erig TC, Zanin RF, Pereira TCB, Bogo MR, Campos MM, Morrone FB. Mechanisms involved in kinin-induced glioma cells proliferation: the role of ERK1/2 and PI3K/Akt pathways. J Neurooncol. 2014;120:235-44.

57. Potier L, Waeckel L, Vincent M-P, Chollet C, Gobeil F, Marre M, Bruneval P, Richer C, Roussel R, Alhenc-Gelas F, Bouby N. Selective kinin receptor agonists as cardioprotective agents in myocardial ischemia and diabetes. J Pharmacol Exp Ther. 2013;346:23-30. 
58. Morissette G, Sabourin T, Adam A, Marceau F. Inhibition of human and rabbit arterial smooth muscle cell migration mediated by the kinin B1 receptor: role of receptor density and released mediators. Can J Physiol Pharmacol. 2006;84:1107-19.

59. Scharfstein J, Ramos PIP, Barral-Netto M. G protein-coupled kinin receptors and immunity against pathogens. Adv Immunol. 2017;136:29-84.

\section{Publisher's Note}

Springer Nature remains neutral with regard to jurisdictional claims in published maps and institutional affiliations.
Ready to submit your research? Choose BMC and benefit from:

- fast, convenient online submission

- thorough peer review by experienced researchers in your field

- rapid publication on acceptance

- support for research data, including large and complex data types

- gold Open Access which fosters wider collaboration and increased citations

- maximum visibility for your research: over $100 \mathrm{M}$ website views per year

At BMC, research is always in progress.

Learn more biomedcentral.com/submissions 